Madrygal. Revista de Estudios Gallegos

ISSN: 1138-9664

\title{
Lembrando ao noso Sabino
}

Xesús Alonso Montero; Vicente Araguas; Manuel Pereira Valcárcel ${ }^{1}$

\section{Sabino Torres, in memoriam ${ }^{2}$}

Deixounos onte ás nove menos cuarto da mañá, en Madrid, na casa da súa filla María. Este verán -como todos os veráns- agardabámolo para recitar poemas - unha das súas paixóns-, para asistir ao Foro de Portonovo e para homenaxear a Borobó, o noso querido e admirado amigo, no centenario do seu nacemento. Sabino Torres Ferrer cumpriría 92 anos o 24 de xuño; cónstame que hai poucos días aínda conversaba con moito entusiasmo na súa casa (in doloris lecto) con Vicente Araguas e outros compañeiros do Grupo Bilbao de Madrid. Falaron de poesía e dunha revista literaria que o grupo madrigalego vai estrear axiña.

Tiña Sabino Torres unha biblioteca de poesía verdadeiramente formidable, pois desde moi novo foi lector devoto de non poucos poetas. Novo aínda, en 1949, creou unha colección de poesía en Pontevedra, a primeira en Galicia despois da Guerra Civil. El e os compañeiros da aventura -Emilio Negreira, José Ruibal, Rafael Alonso...- bautizárona cun nome subversivo, que iso era a poesía naquel tempo mísero e ríspeto: o do pirata Benito Soto, pontevedrés coma eles. $\mathrm{Na}$ colección estreouse Sabino Torres co libro Como el río, en castelán, a lingua na que o noso autor se sentía mellor instalado para as tarefas poéticas e outras tarefas literarias. Excelente poeta, non son desdeñables as súas incursións no galego, entre elas o libro Intres de soidade, que eu lle prologuei (Ediciós do Castro, 2001).
Nos últimos vinte anos dirixiu a colección, por el fundada, Hipocampo Amigo, onde acolleu voces moi distintas da poesía galega, sen excluír as voces republicanas, algunhas moi comprometidas. Cónstame que algúns volumes foron financiados, en parte, por el. Era, pois, editor e mecenas, e érao porque o seu compromiso coa causa poética era moi fondo.

Cando en 1949 inventa a colección Benito Soto, a aventura poética naceu cun aliado moi eficaz: Gráficas Torres, ou sexa, a imprenta pontevedresa do seu pai. Catorce foron os volumes que publicou a colección, oito deles en galego, algúns tan significativos como Dona do corpo delgado (de Álvaro Cunqueiro), Triscos (de Luís Pimentel), Anxo de terra (de Ricardo Carballo Calero), Muiñeiro de brétemas (de Manuel María) e As canciós dise amor que se diz olvido (do poeta andaluz Juan Pérez Creus). Co falecemento de Sabino Torres a causa poética está de loito; tamén os amigos, os moitos amigos deste cidadán ilustrado e machadianamente bo.

Xesús Alonso Montero

\section{Vai túa, Sabino ${ }^{3}$}

A Sabino Torres o que máis lle prestaba, polo que máis devecía, era porque se lle recoñecese o don poético que sen dúbida tiña. $\mathrm{O}$ que pasa é que Camilo José Cela "dixit" (semella mentira ter que lembrar que o padronés foi escritor decisivo, diante do ninguneo cando non

\footnotetext{
Grazas aos contributos destes tres autores, Madrygal ofrece aos seus lectores unha pequena lembranza do mestre Sabino Torres. Publicado por Xesús Alonso Montero en La Voz de Galicia o 24 de maio de 2016.

Publicado por Vicente Araguas en Nordesía núm. 30 (Diario de Ferrol) o 16 de xuño de 2016.
} 
do insulto "post mortem" que lle adica certa "intelligensia", polo demais, cativeira), este país non dá máis que para unha idea. E por iso que o bo de Sabino, tan elegante, tan lanzal, tan dandi, vai quedar, se non o remediamos os que amamos estas cousas, e tamén a Sabino, lástima fora, soamente como editor da aceda posguerra, cando editar en galego era choio ruinoso (e perigoso), da mítica colección de poesía Benito Soto. O catálogo desta colección, auspiciado polo nome dun pirata aforcado en Xibraltar, polos ingleses (que algo souberon -saben- de asuntos corsarios), é dunha riqueza que abraia. Alí estaba o melloriño dunha literatura que non se quería dar por morta. E Sabino Torres indicándolle o Norte. Antes Sabino andivera ao leme da revista Finisterre (ano 1943), e os seus derradeiros días, debo dicilo xa, que me queima na gorxa e máis na man, estiveron adicados á edificación da revista poética Olga, que imos presentar en Madrid, na Casa de Galicia, o 28 deste mes. Olga ben podía terse chamado Bilbao, en honor do grupo vencellado ao Café Comercial, asasinado o verán de 2015, con sede na Glorieta de Bilbao. Por iso. Mais Sabino Torres - ¿el como era fisicamente?, pregúntanme, e eu soamente respondo que imaxinen de maior a seu sobriño, o actor Francis Lorenzo, cuspidiño a Sabino Torres Ferrer, de Pontevedra, esa vila boa ou boa vila á que adicara Sabino algún libro recordatorio das súas mocidades feridas e feridoras (por galantes)- non aceptou o nome. $\mathrm{O}$ noso amigo e capitán rexeitou o nome de Bilbao poisque outra xeira comezaba, agora ao abeiro da veciña Cafetería Santander, e cismando, cismando, batemos con Olga. Como se sabe, pegada na neve e, loxicamente, nome (fermosísimo) de muller. E vimos, vin, a Sabino Torres por vez derradeira cando lle fóramos levar o primeiro número ao seu domicilio de O'Donnell. Onde Sabino Torres, sereno, sabendo o prazo fixo que tiña diante, agardaba á da gadaña con aquel ollar estoico, que era o seu, e o porte elegante de sempre. E así foi e así será a lembranza que nos deixa este home, pioneiro na edición galega logo da guerra. Poeta lírico, en galego e español, facedor de poetas e de poemas, a través das súas publicacións. Como esta que teño diante miña ao escribir a semblanza dorida dun home enteiro. Olga, debida a Sabino Torres, aínda que outros esteamos na súa mancheta. Olga, artellando xa o número inmediato, homenaxe a seu fundador, o inmenso Sabino Torres Ferrer. Sabino, vai túa, e que saibas que para min eras máis que nada poeta. $\mathrm{O}$ que lle escribira á filla morta: "Foi un cravo/ de aleivosas ferruxes, / o que deteu nas sens/ a súa vida./ Agora témolo nós, amor,/ e canto doe". Por exemplo, Sabino, grande. Como exemplo.

Vicente Araguas

\section{Es obvio ${ }^{4}$}

Sabino Torres Ferrer volvía unha noite con outros compañeiros de troula por un camiño que delataba a súa procedencia inequívoca, viñan dunha casa que tampouco deixaba lugar a dúbidas. Nun determinado momento foron requiridos pola Policía: «¿De dónde vienen a estas horas?», «¿Como que de dónde venimos? ¡Es obvio!», foi a resposta arriscada de Sabino.

Esta anécdota contouna varias veces na nosa tertulia do Comercial e nunha versión semellante está rexistrada nun dos dous libros de memorias que nos entregou xa cando se lle ía rematando o tempo de escribir.

Refírome a As tres columnas, obra dedicada á Moureira. Se ben para acoutar o terreo cómpre engadir das putas, para distinguila da outra Moureira, a dos pescadores, e evitar así equívocos e vinculacións rexeitadas. Non só os bordeis son os protagonistas do relato. É toda a cidade de Pontevedra e a súa relación con ese territorio teoricamente á marxe da sociedade, aínda que máis achegado do que se podería pensar. Libro imprescindible para entrar no corazón prohibido dunha vila galega, nun espazo visto de esguello e decorado con lendas cheas de mitos e perversión.

Este libro publicouse no ano 2008, cando Sabino Torres contaba con oitenta e catro anos de idade e conservaba unha marabillosa memoria e unha feliz lembranza daquel tempo. $\mathrm{O}$ recordo dunha mocidade coas limitacións da época, pero na que soubo buscar os seus puntos de fuga, imprescindibles para poder evitar as manufacturas dunha época mediocre. 
Aínda tivo tempo para nos entregar outro libro de memorias, editouse en 2014 e titulábase Crónicas dun tempo escondido. Pontevedra 1930-1960, no que amplía o campo de visión a todos os aspectos da cidade na que naceu e que sempre ocupou o seu corazón e o argumento principal da súa conversa.

Trátase de dúas obras literarias, de dúas crónicas sentimentais, non pretenden ser ensaios históricos nin sociolóxicos. Neles está a emoción e a verdade que o autor quixo gardar de aqueles anos e transmitilos. Por estas obras entendemos que Sabino sempre se moveu por impulsos vitais, antes que por postulados ideolóxicos.

Esa vitalidade, ese espírito de mocidade entusiasta levárono a promover a colección de poesía Benito Soto xunto cos amigos que o quixeron secundar: Celso Emilio Ferreiro, Rafael Alonso, Emilio Álvarez Negreira, Manuel Cuña Novás, entre outros. No seu xesto había, penso eu, máis inconsciencia e ousadía ca intención política. Dese xeito naceu a primeira colección de poesía da posguerra en Galicia. Non se trataba, como se sabe, dunha colección poética galega exclusivamente, pois saíron libros en castelán tamén.
Nos seus anos de dedicación profesional a unha tarefa que nada tiña que ver coa literatura seguiu cultivando a poesía, pois ese era o seu desexo máis firme, ser poeta. Non rexeitaba os afagos que lle fixeron coma editor, pero preferiría ser lembrado coma poeta. Que, sen dúbida, foi; de verso puído e sinxelo, medido e musical. O que sucede é que os méritos de Benito Soto eran moitos. E, ademais, cando se reincorpora ao mundo literario, decontado volve editar. Neste caso a colección chámase Hipocampo amigo, publicando libros de poesía en galego e en castelán, como sucedera na primeira etapa.

Estes son libros maquetados por el no seu ordenador, pois a súa relación coas novas tecnoloxías era doada, pero á vez manteñen a pegada do vello impresor. Antes de seren encadernados, cosíaos á man e coloraba os debuxos das portadas tamén de xeito artesanal.

Sabino Torres soubo retornar á literatura con naturalidade e sinxeleza. Pronto se converte en testemuña única dunha época literaria pontevedresa, xa que a morte chamou antes a todos os seus compañeiros de xuntanzas. Nel tivemos un relator doutro tempo, unha fonte de consulta e memoria constante. Tamén un amigo

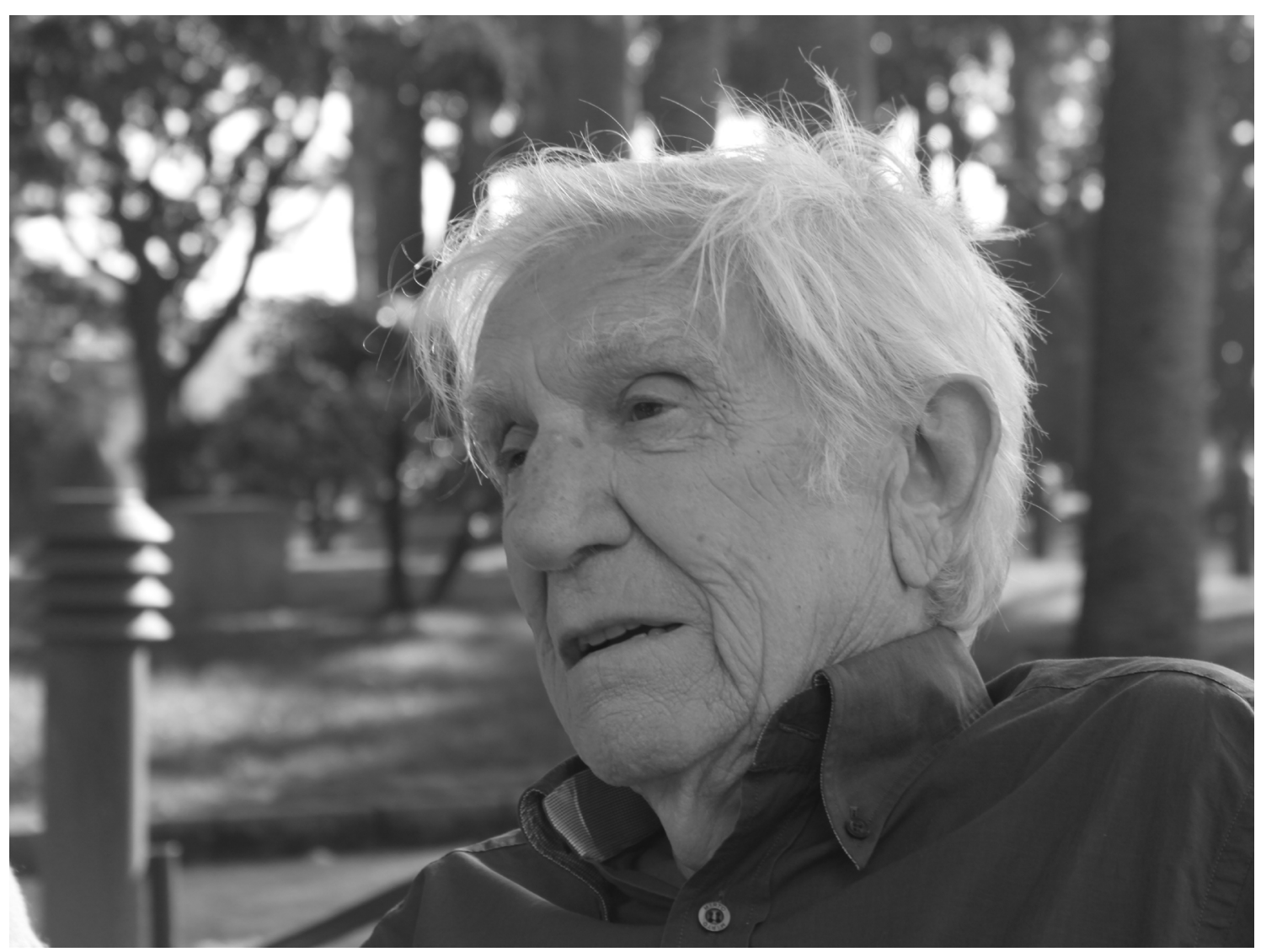


con proxectos novos que defendía e impulsaba incansablemente. O último, a revista poética Olga da que saíu o primeiro número e está en camiño o segundo. O seu nacemento foi un empeño persoal del que prendeu noutros tres membros do grupo Bilbao: Vicente Araguas, Rafa Yáñez e quen asina este artigo.

Dous foron os lugares de referencia de Sabino en Pontevedra. O café Savoy durante moitos anos e despois, cando este pechou, mudou a súa estación para o Hotel Rías Bajas; Rías Baixas, para nós. En calquera deles recollían todo tipo de avisos e encomendas para el. Eran a súa dársena, o seu lugar para o encontro e a conversa, para a palabra amigable e o convite xeneroso.
As cidades constrúense con diferentes materiais e teñen unha forma que nos vén dada. Nós buscamos itinerarios, eliximos espazos e fragmentos, asociámoslles músicas, voces e olladas até que as facemos enteiramente nosas. Superpoñemos unha forma sentimental sobre a estrutura física imposta.

Unha cidade é moitas cidades, igual que unha rosa é moitos corazóns. A personalidade que ten para nós Pontevedra é debida en boa parte á relación con Sabino. Seguiremos amándoa e frecuentándoa. Aínda que debamos soportar o baleiro, a distancia, o frío. Es obvio.

Manuel Pereira Valcárcel 